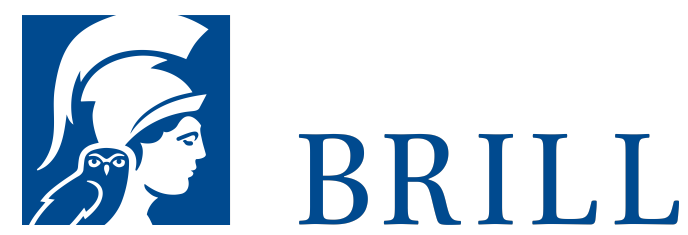

\title{
Platons Semantik
}

Die Theorie sprachlicher Bedeutung im Kratylos

Author: Christoph Diehl

Platons Dialog Kratylos thematisiert eine der Grundfragen philosophischer Semantik: Wie erlangen die Ausdrã $1 / 4$ cke unserer Sprache ihre spezifischen Bedeutungen? Platon diskutiert zwei mÃ $₫$ gliche Antworten: Entweder sprachliche AusdrÃ $1 / 4$ cke gewinnen ihre Bedeutung durch soziale Ãœbereinkunft (Bedeutungskonventionalismus) oder durch eine 'nat $\tilde{A} 1 / 4$ rliche' Beziehung (Bedeutungsnaturalismus) zu ihren Trẫogergegenstãønden. Die vorliegende Studie unternimmt den Versuch, Platons Ãœebrlegungen zum Begriff der Bedeutung als eine kohÃarente Theorie zu deuten, die beide Positionen inkorporiert. Es werden die zeitgen $\tilde{\text { I ssischen }}$ semantischen AnsÃatze Putnams und Griceâ $€^{\text {max }}$ eingefÃ $1 / 4$ hrt und interpretatorisch auf den platonischen Dialog angewendet. Im Zuge der Untersuchung werden die epistemologischen BezÃ $1 / 4$ ge von Platons Semantik aufgezeigt und eine innovative Lesart der platonischen Position generell vorgeschlagen. So wird gezeigt, dass Platon in der Geschichte der Sprachphilosophie bisher zu Unrecht vernachlãassigt worden ist.

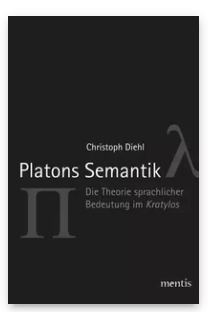

Pages: 162

Seiten

Language:

German

Subjects:

General,

Philosophy

Publisher: Brill | mentis

E-Book (PDF)

Released online:

o1 Aug 2012

ISBN: $978-3^{-}$

89785-944-9

List price

USD Â $\$ 40.00$

Paperback

Publication date:

o1 Aug 2012

ISBN: $978-3^{-}$

89785-766-7

List price

US.D. Â $\$ 40.00$ 
For more information see brill.com

Order information: Order online at brill.com +44330 333 0049 | customerservices@brill.com Submission information: brill.com/authors

Titles published by Brill | Fink, Brill | mentis or Brill | Schöningh: +49(o)715413279216| brill@brocom.de 